Information Management and Business Review

Vol. 5, No. 6, pp. 270-277, June 2013 (ISSN 2220-3796)

\title{
Technostress: Mediating Accounting Information System Performance
}

\author{
M. U. Saganuwan*, W. K. W. Ismail, U. N. U. Ahmad \\ Universiti Teknologi Malaysia, Malaysia \\ *umsagan@yahoo.com
}

\begin{abstract}
In recent times, Accounting Information System (AIS) characteristics were studied to enhance its effectiveness but the impact technology stress, which imposes additional stress in the professionals known as techno stress, is not reflected. Technostress and AIS literatures were reviewed to synthesize the relationship. Technostress adversely affect the professional's job satisfaction and performance. Therefore, this conceptual paper highlights and synthesizes the issues of techno stress with professionals and the effectiveness of AIS in organizations. However, based on the strength of existing frameworks of AIS, techno stress use to mediate the technological, organizational and cognitive contingency factors under condition of uncertainty to determine AIS effectiveness.
\end{abstract}

Keywords: Technostress, AIS Effectiveness, Job Satisfaction, Job Performance, Digital Economy

\section{Introduction}

Technology otherwise known as Information and Communication Technology (ICT) is used today to accomplish tasks in organizations. AIS are a complex subsystem of ICT that requires the users (professional accountants and managers) to use many applications to obtain varieties of qualitative information for planning, control functions and decision-making. The AIS processes placed on the professional's constant connectivity, information overload, continual upgrades in technology, technical problems associated with the use of technology may affect techno stress. Conversely, technostress is said to adversely affect professional's job satisfaction and reduces their productivity (Tarafdar, Tu, Ragu-Nathan, \& Ragu-Nathan, 2011) which can be linked directly to organizational performance. Therefore, this puts to question the AIS performance in the context of professional is job satisfaction and performance. Basically techno stress is generally experienced when the user is struggling to use and/or over-identifying with technology to perform tasks in the organization(Brod, 1984). Technostress is described as the etiology of many diseases like cardiovascular disorder, hypertension and psychosomatic ailments. However, irrespective of what causes occupational stress in employees, it has been found to have an adverse effect on organizations. For example, the maintenance supervisors experienced more stress in computer-based plant than in traditional plant(Blake, Saleh, \& Whorms, 1996). Also, according to Croon, Kuijer, Broersen, \& Frings-Dresen, (2004)the introduction of an OBC - system in Dutch road transport system negatively affect the lorry driver's job. In view of the above AIS, usage should be associated with techno stress and should affect the professional vis-a-viz organizational performance. Therefore, the effects of techno stress may cause professionals to experience lower productivity, job dissatisfaction, and high amounts of absenteeism turnover among others.

Consequently, there is missing link between the effectiveness of AIS in the organizational context and the effect of techno stress on the professionals with respect to job satisfaction and organizational performance. However, this conceptual paper will further extend the research of the effectiveness of AIS by incorporating techno stress using Person-Environmental Theory as an addendum that influence AIS effectiveness in organizational performance. Recognizing the concept of techno stress and AIS effectiveness, techno stress idea would be applied in this gap to enunciate a model that will bring into account the effect of techno stress on job satisfaction and job performance to determine the effectiveness of AIS in the context of organizational performance. Specifically, literature were drawn from the fields of techno stress related issues of job satisfaction and job performance and effectiveness of AIS in relation to organizational performance to develop a conceptual framework. The framework will be validated subsequently as this is a research-inprogress. The paper contributes to the literature on the AIS performance which is described by Fowzia \& 
Nasrin (2011) as the lifeblood of competitive organization; again extend the literature on techno stress which has so far given little attention to the study of technology, AIS in particular.

\section{Technostress}

The problem associated with technology usage was identified by Craig Brod in 1984 as techno stress. Technostress is a modern disease that is affecting the generality of the populace. Nonetheless, Weil \& Rosen (1997) posited that today's technology is no longer a novelty but an integral part of our lives and people can't function without it. However, Brod (1984) cautioned that our love for technologies/ICTs is blind and we devote long hours on it at work and play without seeing the possible consequences of its usage. Shu, Tu, \& Wang (2011) study revealed that health related problems such as cardiac arrest, migraine headaches and hypertension are associated with technostress. The symptoms and effects of technostress include persistent negative thinking, momentary confusion, inability to concentrate, poor judgment, distorted ideas, mental fatigue depression, anxiety, irritability and impatience. Ofua \& Pereware (2011)exploratory study outlined the causes/sources of techno stress to include the pace of technological change, inadequate training, increased information/workload, standardization problems, reliability of hardware and software, poor user interface, less involved in the decision making process, slow network, increasing users demand, health related issues of technology usage and complicated work environment. In addition, internet security (viruses), language / jargons of technology, system breakdown, increase management expectation, aged technology (software and hardware), software application problems, obsolete computer skills and unavailability of technical support as among the causes of techno stress in the organizations.

Precisely, Tarafdar, Tu, Ragu-Nathan, \& Ragu-Nathan (2007) refer to the causes as techno stress creators to include techno-overload (forced the user to work faster for long hours), techno-invasion (reach out to the user anytime regardless work hours), techno-complexity (intricate of the technology threatened users' skills), techno-insecurity (users feel threatened of being replaced by more skilful candidates) and technouncertainty (the pace of change make the users unsettled). Meanwhile, they described techno stress inhibitors as organizational mechanisms that affected on techno stress to reduce/lessen its effects on the users of technologies. Empirical evidence revealed that techno stress has negative effects on the users of technology, which in turn have an adverse effect on productivity and job satisfaction (Tarafdar et al., 2011). Also, studies suggested that technostress is higher among professionals that uses technology to accomplish their tasks(Agbu \& Simeon, 2011;Ayyagari, 2007, Ayyagari, 2012,Schuldt \& Totten, 2008)and it has impacted on their task performance in the organization. In spite of the effects of techno stress on both individuals and organizational performance, techno stress inhibitors are discovered by Tarafdar, et al. (2007) to help alleviate its effects, which their studies have identified to be the provision of training, technical support, user involvement among others. Therefore, the negative impact of technostress on the professionals using AIS in the workplace cannot be overemphasized especially on the related issues of job satisfaction and job performance which culminates into organizational performance.

The Impact of technostress and Job Satisfaction and Performance: Griffin \& Moorhead (2010) simply assert that job satisfaction "is the extent to which people find gratification or fulfillment in their work." Similarly, McShane \& Glinow (2010) described job satisfaction as "an evaluation of perceived job characteristics, work environment, and emotional experiences at work." While job performance is defined as "all the behaviors employees engage in while at work" (Jex, 2002). However, the impact of technostress on job satisfaction and job performance is gaining deserved recognition from the management of organizations. This is evident that users' satisfaction is a surrogate for the decreasing technostress as well as the success of an information system in the organizations (Tarafdar, et al.,2011). Many theories were used by scholars in attempting to explain the antecedents and consequences of job satisfaction. This led to the factors that are associated with job satisfaction to include commitment, performance, turnover, absenteeism, well-being and general life satisfaction (Chatzoglou, Vraimaki, \& Komsiou, 2011). Therefore, job dissatisfaction is negatively associated with a strain which can lead to poor job performance (Tarafdar et al., 2007). Although, McShane and Von Glinow (2010) argued that employees may be dissatisfied with their jobs but can improve their performance as some will be waiting to leave, sees the situation as temporary or leave with it. For instance, the introduction of technology turned-on the employees $24 \mathrm{hrs} / 7$ days and the productivity improved but the finding suggested that they suffers severely malady of technostress (Gendreau, 2007). 
Tarafdar et al.(2007) submitted that technological changes have determined the work progress of the users by dictating the pace and timing of action to take, causes job dissatisfaction relationship because of lack of control, task difficulty and increase work demand. Therefore, technostress creators decrease job satisfaction and reduces productivity resulting from the effect of technology on tasks, flow of work and processes involved (Dhar \& Dhar, 2010; Rose, Stoklosa, \& Gray, 1998). Most importantly, Thomée, Eklöf, Gustafsson, Nilsson, \& Hagberg (2007) declared that combining ICTs to accomplish tasks in an organization is associated with prolonged technostress and have serious impact on the psychological health of the user. This verified research finding that academic staff of business faculty was adversely affected by technostress but the effect of technostress was more prominent among the online lectures (Schuldt \& Totten, 2008). Again, multitasking forces the users to respond to work-related information and left them with little time to spend on sustained thinking and creative analysis (Walz, 2012).

Technostress could be manage or reduce through inhibitors which Tarafdar et al. (2011) described as a mechanism that organizations can be used to moderate the causes and outcomes of the modern disease (technostress). Prior study Al-Fudail \& Mellar (2008) revealed that inadequate or insufficient training and technical support are listed among the factors that create technostress in the users of technology. Notwithstanding, empirical evidence suggests that the technostress creators reduce job satisfaction while technostress inhibitors increases job satisfaction (Tarafdar et al., 2011). Similarly, Ayyagari (2012) confirmed that better technology management strategy (inhibiting) increases job satisfaction. To this end, technostress that is triggered by the use of technology have negative effects on the users because it dictates the pace and timing of task performance, involves use of varieties of ICTs and impose multitasking with the resultant effect of job dissatisfaction and decrease in job performance. However, these effects can best be managed using the technostress inhibitors to increase user job satisfaction which has reciprocal effects on job performance.

AIS Usage: Technology has undeniably changed the way professionals work and learn in this information age. The role of technology is being defined in almost all the professions and is constantly being improved upon to bring about efficiency and effectiveness in professional performance. Electronic Accounting Information System or Automated Accounting information System is the intersection of two disciplines of accounting and information system. AIS is a revolution which started in the early 1950's (Nash, 1998) and it is described as the application of information technology in accounting systems that collect and process data through procedures to create the information needed by the users. AIS is computer-based system that processes financial transactions and non-financial transactions and support decision task in the context of coordination and control of organizational activities (Mollanazari \& Abdolkarimi, 2012). It has five components namely inputs, processes, storage, output and internal control and is applicable under the condition of certainty, risk and uncertainty. More so, Yau \& Auyeung (1995) asserts that it is unthinkable to have information in an organization that is not, in a way, linked with AIS. The relationship between AIS and information sources and their connections is shown in figure 1.

Figure 1: AIS and Management Functions. Source: Yau and Auyeung (1995)

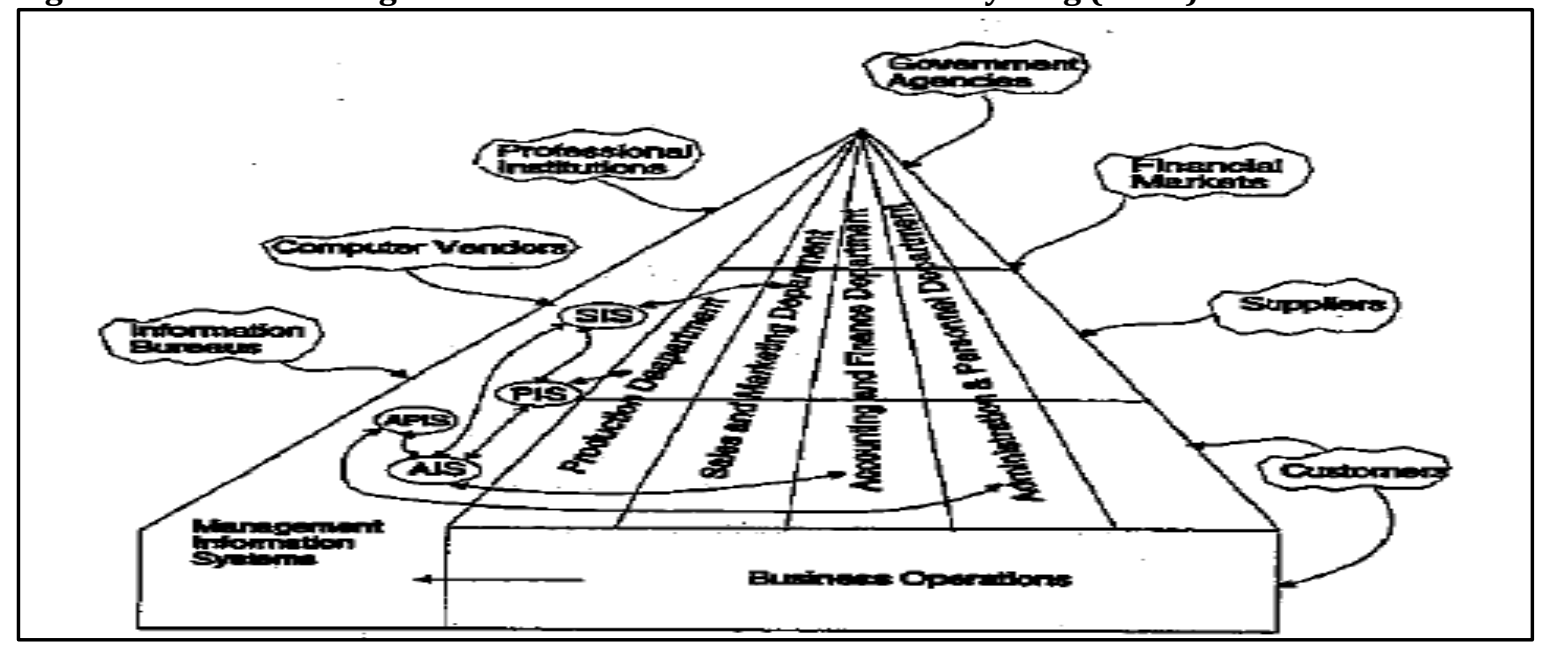


Therefore, the processed information is the ingredients of decision making, internal control functions and planning in the organizations. Nevertheless, Boockholdt (1999), defined it as a system that gather, process, categorize and reporting data of financial events with the objectives of score keeping, attention directed and decision making in organization management. Consequently, AIS can be defined as a subsystem of information technology that collect, process, sort, report and disseminate organization's data systematically for effective performance of management functions and other related tasks. The concept of AIS is well entrenched in the accounting profession through tailor made and off the shelf systems. The information provided by AIS is in two categories: information required for control purposes and information required for coordination purposes. The former influence decision making while the later facilitate decision making process (Markus \& Pfeffer, 1983). It is therefore clear that AIS plays a critical role in organizational mechanism as it enhances managerial functions. Hence, to determine the effectiveness of AIS in organizations it must fit dominant view in the organization, the technology for the organization and the culture of the organization (Markus and Pfeffer, 1983). Also, Naranjo-gil, (2004)claimed that the effectiveness of AIS is contingent on certain external and internal factors, for example, technology and strategy. To this end, the recent trends in this research field of the AIS effectiveness under the condition of uncertainty is determined in the alignment between the organizational strategy and the system (Jawabreh \& Alrabei, 2012; Hajiha \& Azizi, 2011). This is demonstrated in the figure 2

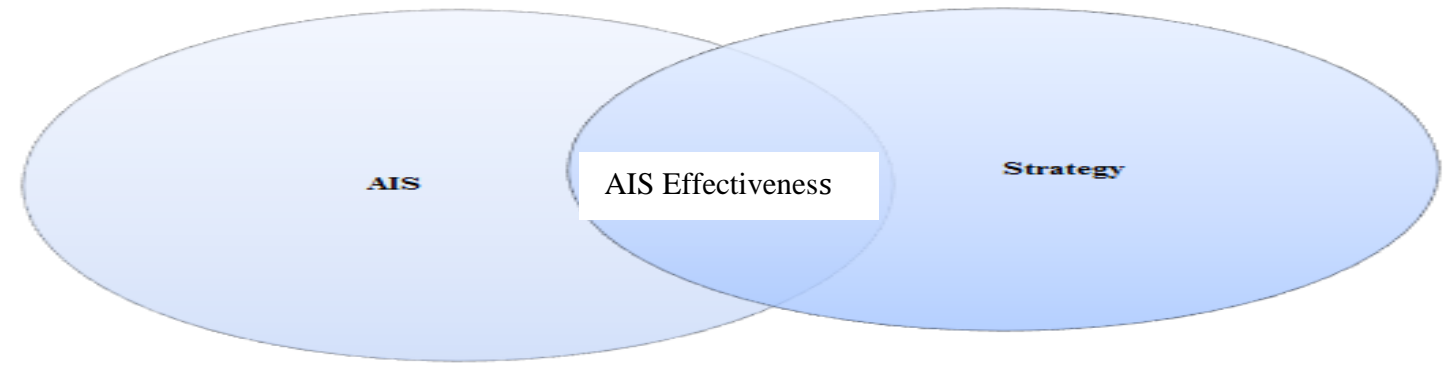

This implies that a misfit or disequilibrium between the strategy and AIS will create friction between the components which prevent the organizations from performing (Chenhall, 2003); this will pose challenges to the organizations especially in the present digitalized economy. Besides, Romney \& John (1997) concluded that based on the research trends AIS enables the professionals to identify the organizational problems, collect the necessary data, select appropriate methods of solving the problems and chooses among the best alternatives. Therefore, effectiveness of AIS is very sensitive to the organization's performance and that makes it imperative to study various factors that will enhance the usefulness and functionality. There are three different approaches to the study of AIS effectiveness in the organizations: contingency, Agency and Transaction Costs Economics Approaches (Mauldin and Ruchala, 1999). Contingency approach is commonly used to explain the equilibrium between the AIS and organizational strategy in the present environmental uncertainty (digital economy). The study of effectiveness of AIS in relation to the professionals is centered on the information characteristics of AIS with authors having varying opinions. However, recent studies use a scope, timeliness and aggregation to study the influence of the effectiveness (Mollanazari \& Abdolkarimi, 2012, Al-kasswna, 2012). Nonetheless, the studies are having somewhat contradictory results with respect to organizational performance. Soudani (2012) review claimed that the introduction of AIS improves organization's performance in Spain, Finland, Malaysia, Pakistan and Iran. Fowzia and Nasrin (2011) in their study of financial institutions and non-governmental organization attested to this claim. Onaolapo \& Odetayo (2012) discovered AIS was effective but its relationship with organizational performance was weak. Similarly, Jawabreh and Alrabei (2012) uncovered that there is no relationship between AIS and management functions in the studied five star hotels in Malaysia.

In addition, Grande, Estébanez, \& Colomina (2011) studied SMEs using AIS and confirmed that it has little impact on the organizational performance and high impact on fiscal and banking transactions. However, evaluating the effectiveness of this system by Sajady, Dastgir, \& Nejad (2008) revealed that it impacted positively on manager's decision making, internal control system, quality of financial reporting and facilitate a 
financial transaction process in the Bangladesh organizations. These results suggest that there may be a missing factor (technostress and its inhibitors) that it's present or not present in the studied organizations may be responsible for some of these contradictions. Even though some studies have shown the effectiveness of AIS, the effectiveness of AIS does not necessarily influence job satisfaction and performance. In spite of the contradictions in the outcome of empirical research on AIS effectiveness, user satisfaction was studied in relation to the use of this system and the result indicates that the professionals were satisfied with the usage (Fowzia and Nasrin, 2011, Mollanazari and Abdolkarimi, 2012).Even though Mollanazari and Abdolkarimi, (2012) investigation highlight two conditions that influence manager's satisfaction with the system without which they may be dissatisfied. Noticeably, these studies focus on the user's satisfaction with the system but not with the other contingency factors (organizational and cognitive factors) to portray the exact picture of the AIS effectiveness situation in relation to job satisfaction and job performance in the organizations. However, technostress research studies indicated that the use of technology causes technostress and technostress has a negative effect on job performance; therefore, technostress can be linked to job dissatisfaction that which promote low productivity among user (Tarafdar et al.,2011). AIS usage therefore may be linked with technostress attributes that would be discussed in the next section.

\section{Technostress in AIS}

AIS is a vital tool in the organization that assists professionals in understanding their role better and provide the necessary information for effective management functions (Sajady et al., 2008). It offers organizations a substantial competitive advantage because it facilitates strategic management and increase organizational performance. In other words, the AIS is used by professionals for effective decision making, planning and control functions ensure competitiveness of the organizations in the digitalized economy. Nevertheless, there are conditions that can create technostress in the professional's usage oafish. AIS is a logical network connectivity of both internal (associates) and external (departments) environments of business that provide coordination and easy location of problems in the system (Yau and Auyeung, 1995). Therefore, slowness and interruption in the internet could lead to information overload or multitasking which Tarafdar et al.(2011) asserts that users are exposed to more information than they can efficiently and effectively handle and use respectively. This may be more peculiar to the influence of the broad scope characteristic of the AIS which Mollanazari and Abdolkarimi (2012) warned that it can lead to ineffectiveness of the system. Also, working with different software aggravate tension with the users and AIS is a collection of accounting software which may include Mind Your Own Business, Quick Books, Cash Flow Manager, Attache, System Opera Software and so on. Therefore, AIS can create technostress in the users (professionals) since it possess the attributes of technostressors.

For instance, Walz (2012) investigations also revealed that ICT allowed professional to be reached anywhere at anytime which implies blurring boundaries between home-work. So, AIS has attributes of techno-invasions shown in figure 1, this persuades the professionals attend to official matter even after office work hours. The unrelenting pace of change in technology is another source technostress to the users. However, this is evident in the dynamism in many AIS software that are available for accounting purposes. Of course, there must be an equilibrium between the technology and strategy as provided in the AIS effectiveness framework to attain organizational performance. Nonetheless, integrating of the concept of technostress to mediate between the professional's job satisfaction and performance would present a more encompassing effectiveness of AIS to determine organizational performance. The relationship in this integration shows the effectiveness of AIS at the point of the intersection of the triple helix as shown in the figure 3. 


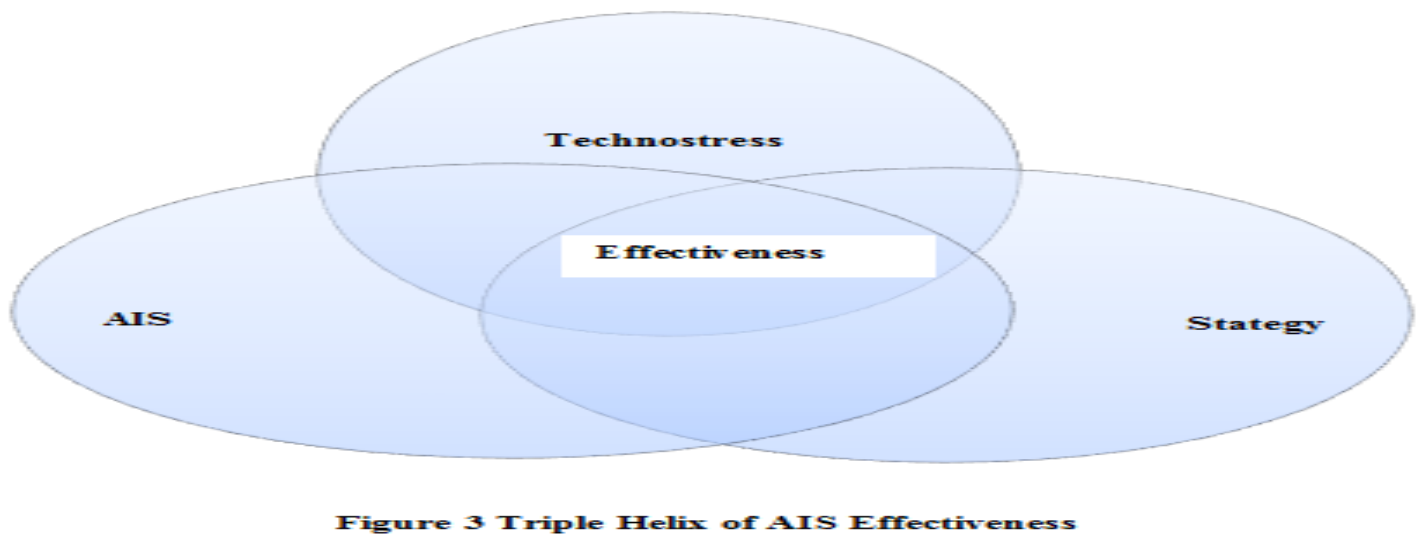

\section{Conceptual Framework}

The contingency approach under the condition of uncertainty was used to explain the effectiveness of AIS in organizations, however the outcome (effectiveness of AIS) would be rated inadequate as it only focuses on fits between organizational strategy and AIS. In this context the concept of AIS effectiveness would be extended by infusing the concept of technostress into it using person-environmental theory. Person-environment theory, which states that there should be an equilibrium between the individuals and their work environment is used to explain technostress phenomenon in professionals (Tarafdar et al.,2011; Ayyagari, 2011). Consequently, there are two ways in which imbalance could occur; (1) the imbalance between the professionals and their organizational task performance by using AIS, could result in a stressful situation when the professionals are unable to meet the organizational expectations, and. (2) The imbalance between professional's values that do not suit organizational task performance by using AIS, could also result in a stressful situation when the organizational task performance cannot meet these values. Therefore, personenvironmental theory would be used to extend the study of effectiveness of AIS by incorporating the concept of technostress as described in the model presented in figure 4.

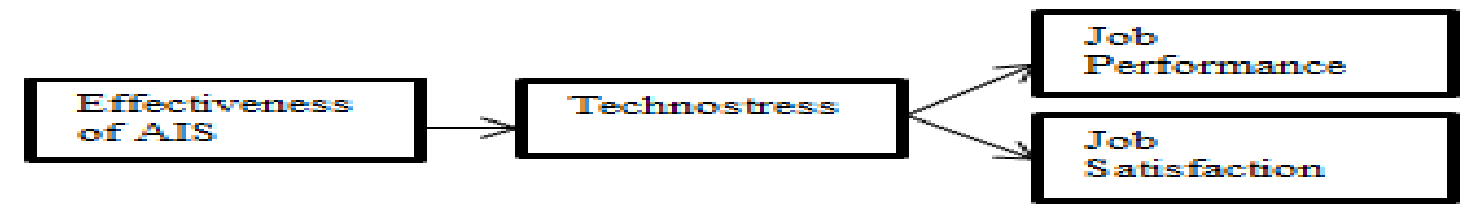

Figure 4: Comoeptual Framewrotk

\section{Conclusion}

Technostress is an important phenomenon that needs to be addressed by organizations that uses AIS to achieve their objectives because it contributes to unhealthy psychological well-being of the professionals as its impact on their job satisfaction and job performance. Therefore, AIS as tools in discharging management functions and related tasks need to be effective because of the important role it's playing in organizations. Therefore, this conceptual paper contributes to technostress research by integrating the concept of technostress with the AIS usage, with technostress having mediating influence on professional's job satisfaction and job performance. Also, the paper contributes to the AIS effectiveness research by extending the research on AIS performance in the organizations. As a research-in-process, it is hoped that the empirical test that would be provided in this study would offer opportunity for organizations, especially the listed companies, to address technostress to determine AIS effectiveness. 


\section{References}

Agbu, J. F. O. \& Simeon, O. K. (2011). Technostress in the age of information communication technology : A case study of distance education. Educational Research, 2(11), 1654-1660. Retrieved from http://www.interesjournals.org/ER

Al-Fudail, M. \& Mellar, H. (2008). Investigating teacher stress when using technology. Computers \& Education, 51(3), 1103-1110.

Al-kasswna, R. O. (2012). Electronic Accounting Information Systems Efficiency in Energy Sector under Conditions of Uncertainty - A Field Study Electricity Companies in the Hashemite Kingdom of Jordan. Research Journal of Finance and Accounting, 3(5), 16-30.

Ayyagari, R. (2007). What And Why Of Technostress: Technology Antecedents And Implications. Clemson University.

Ayyagari, R. (2012). Impact Of I Nformation O Verload And T Ask - Technology F It. Proceedings of the Southern Association for Information Systems Conference, (18-22). Atlanta, GA, USA.

Blake, C. G., Saleh, S. D. \& Whorms, H. H. (1996). Stress and satisfaction as a function of technology and supervision type. International Journal of Operations \&Production Management, 16(5), 64-73.

Boockholdt, J. (1999). Accounting Information Systems Transaction Processing and Control. The Mac-GrawHill companies.

Brod, C. (1984). Technostress: The human cost of the computer revolution. Reading MA: Addison Wesley.

Chatzoglou, P. D., Vraimaki, E., \& Komsiou, E. (2011). Factors Affecting Accountants ' Job Satisfaction and Turnover Intentions : A Structural Equation Model, (July), 11-12.

Chenhall, R. H. (2003). Management control systems design within its organizational context : findings from contingency-based research and directions for the future. Accounting, Organizations and Society, 28, 127-168.

Croon, E. M. de, Kuijer, P. P. F. M., Broersen, J. P. J. \& Frings-Dresen, M. H. W. (2004). Information Technology and Road Transport Industry: how does IT affect the lorry Driver? Applied Ergonomics, 35, 313-320.

Dhar, R. L. \& Dhar, M. (2010). Job stress, coping process, and intentions to leave: A study of information technology professionals working in India. The Social Science Journal, 47, 560-577. doi:10.1016/j.soscij.2010.01.006

Fowzia, R. \& Nasrin, M. (2011). Appreciation of Computerized Accounting System in Financial Institutions in Bangladesh. World Review of Business Research, 1(2), 1-9.

Gendreau, R. (2007). The new techno culture in the workplace and at home. Journal of American Academy of Business, 1(2).

Grande., E. U., Estébanez., R. P. \& Colomina., C. M. (2011). The impact of Accounting Information Systems (AIS ) on performance measures : empirical evidence in Spanish SMEs 1. The International Journal of Digital Accounting Research, 11, 25-43. doi:10.4192/1577-8517-v11

Griffin, R. W. \& Moorhead, G. (2010). Organisational Behavior: Managing People and Organisations (Ninth edit.). Mason, USA: SOUTH-WESTERN CENGAGE Learning.

Hajiha, Z. \& Azizi, Z. A. P. (2011). Effective Factors on Alignment of Accounting Information Systems in Manufacturing Companies: Evidence from Iran. Information Management and Business Review, 3(3), 158-170.

Jawabreh, O. A. \& Alrabei, A. M. (2012). The Impact of Accounting Information System in Planning, Controlling and Decision-Making Processes in Jodhpur Hotels. Asian Journal of Finance \& Accounting, 4(1), 173188. doi:10.5296/ajfa.v4i1.1435

Jex, S. M. (2002). Organizational Psychology: A Scientist-Practitioner Approach. New York: John Wiley.

Markus, M. L. \& Pfeffer, J. (1983). Power, and the Design and Implementation of Accounting and Controlling Systems. Accounting, Organization and Society, 8(2-3), 205-218.

McShane, S. L. \& Glinow, M. A. V. (2010). Organisational Behavior: emerging knowledge and paractice for the real world (Fifth edit.). New York: McGraw-Hill Irwin.

Mollanazari, M. \& Abdolkarimi, E. (2012). The Effects of Task, Organization and Accounting Information Systems Characteristics on the Accounting Information Systems Performance in Tehran Stock Exchange. International Journal of Innovation, Management and Technology, 3(4), 443-448.

Naranjo-gil, D. (2004). The Role of Sophisticated Accounting System in Strategy Management. The International Journal of Digital Accounting Research, 4, 125-144.

Nash, J. F. (1998). Accounting Information Systems (Second edi.). PWSKent Publishing Company. 
Ofua, O. J. \& Pereware, T. A. (2011). Technostress. International Journal of Digital Library Systems, 2(4), 24-33. doi:10.4018/jdls.2011100103

Onaolapo, A. A. \& Odetayo, T. A. (2012). Effect of Accounting Information System on Organisational Effectiveness : A Case Study of Selected Construction Companies in Ibadan, Nigeria. American Journal of Business and Management, 1(4), 183-189.

Romney, M. B. \& John, S. P. (1997). Accounting Information Systems. (Singapore) Pte. Ltd, India: Pearson Education.

Rose, P. M., Stoklosa, K. \& Gray, S. A. (1998). A Focus Group Approach to Assessing Technostress at the Reference Desk. American Library Association, 37(4), 311-317. Retrieved from http://www.jstor.org/stable/20863337

Sajady, H., Dastgir, M. \& Hashem, N. H. (2008). 49 Evaluation of the Effectiveness of Accounting Information Systems International Journal of Information Science and Technology. International Journal of Information Science and Technology, 6(2), 49-59.

Schuldt, B. A. \& Totten, J. W. (2008). Technological Factors \& Business Faculty. Proceedings of the Academy of Information and Management Sciences, 12(1), 13-19.

Shu, Q., Tu, Q. \& Wang, K. (2011). The Impact of Computer Self-Efficacy and Technology Dependence on Computer-Related Technostress: A Social Cognitive Theory Perspective. International Journal of Human-Computer Interaction, 27(10), 923-939. doi:10.1080/10447318.2011.555313

Soudani, S. N. (2012). The Usefulness of an Accounting Information System for Effective Organizational Performance. International Journal of Economics and Finance, 4(5), 136-145. doi:10.5539/ijef.v4n5p136

Tarafdar, M., Tu, Q., Ragu-Nathan, B. \& Ragu-Nathan, T. (2007). The Impact of Technostress on Role Stress and Productivity. Journal of Management Information Systems, 24(1), 301-328. doi:10.2753/MIS07421222240109

Tarafdar, M., Tu, Q., Ragu-Nathan, T. S. \& Ragu-Nathan, B. S. (2011). Crossing to the dark side. Communications of the ACM, 54(9), 113. doi:10.1145/1995376.1995403

Thomée, S., Eklöf, M., Gustafsson, E., Nilsson, R. \& Hagberg, M. (2007). Prevalence of perceived stress, symptoms of depression and sleep disturbances in relation to information and communication technology (ICT) use among young adults - an explorative prospective study. Computers in Human Behavior, 23, 1300-1321.

Walz, K. (2012). Stress Related Issues Due to Too Much Technology: Effects on Working Professionals. Johnson \& Wales University ScholarsArchive@JWU. Retrieved from http://scholarsarchive.jwu.edu/mba_student

Weil, M. M. \& Rosen, L. D. (1997). Technostress: Coping with technology @ Work @ Home @ Play. New York: John Wiley.

Yau, C. \& Auyeung, P. K. (1995). Issues of Accounting information system for the Year 2000. PACIS conference 1995. Retrieved from www.pacis-net.org/file/1995/99.pdf 